\title{
A RARE CASE OF PNEUMATOSIS CYSTOIDES INTESTINALIS AFTER APPENDICECTOMY
}

\author{
Gale Kathleen Edward1, Divyashree B. N², Sangireddy33, Kanu Venkateshwara Reddy4
}

${ }^{1}$ Consultant Pathologist, Elbit Medical Diagnostics Limited.

${ }^{2}$ Consultant Pathologist, Elbit Medical Diagnostics Limited.

${ }^{3}$ Surgical Oncologist, Balaji Multispeciality Hospital, Madanapalle.

${ }^{4}$ General Surgeon, Balaji Multispeciality Hospital, Madanapalle.

HOW TO CITE THIS ARTICLE: Edward GK, Divyashree BN, Sangireddy, et al. A rare case of pneumatosis cystoides intestinalis after appendicectomy. J. Evolution Med. Dent. Sci. 2017;6(48):3731-3732, DOI: 10.14260/Jemds/2017/805

\section{PRESENTATION OF CASE}

A female aged 42 years, presented with acute lower abdominal pain to the surgical OPD. Imaging studies showed only a fibroid uterus. Intraoperative findings showed a swollen appendix and appendicectomy procedure was performed along with hysterectomy. The specimens of resected appendix, uterus and cervix were received in the Department of Histopathology at Elbit Laboratories. Gross finding showed a yellowish solid lesion measuring $2 \times 1 \mathrm{cms}$ involving the tip and mid part of appendix. Microscopy showed a well-differentiated neuroendocrine neoplasm (low grade) involving tip, mid part and small part of the base. Immunohistochemistry studies using chromogranin and Ki67 markers confirmed the diagnosis. Histological findings in uterus and cervix confirmed the presence of leiomyoma. Patient presented for routine post-operative checkup 2 months later and radiological findings postoperatively showed an ill-defined soft tissue lesion with nodular calcification seen anterior to ascending colon. A right hemicolectomy was performed. Gross findings showed a grey white ill-defined neoplasm measuring $5 \times 4 \times 3 \mathrm{cms}$ at the ileocaecal junction. Cut sections showed few tiny slit-like spaces. Microscopy revealed many cyst spaces lined by macrophages and occasional multinucleated giant cells, predominantly in the subserosal layers. Adjacent tissue showed chronic inflammatory reparative changes (Figure 1). Pneumatosis cystoides intestinalis is a rare disorder, characterised histologically by the presence of multiple gas filled cysts in the subserosal or submucosal wall of the large or small intestine. ${ }^{1}$ Pneumatosis cystoides intestinalis occuring in infants is usually seen as a component of necrotising enterocolitis and often has a fatal outcome. Exceptionally, it occurs in association with multiple sclerosis. In adults, it may present as an idiopathic finding or in association with mechanical intestinal obstruction, chronic lung disease or scleroderma. When not associated with other abnormalities, it follows a chronic and indolent course and may produce signs of intestinal obstruction and lead to an incorrect radiographic diagnosis of carcinoma. ${ }^{2}$ The case

Financial or Other, Competing Interest: None.

Submission 20-02-2017, Peer Review 02-06-2017,

Acceptance 09-06-2017, Published 15-06-2017.

Corresponding Author:

Dr. Gale Kathleen Edward,

Elbit Medical Diagnostics Limited,

Indian Express Building, 1 \& 1/2,

Queens Road, Bangalore- 560001,

Karnataka, India.

E-mail: galekathleen@gmail.com

DOI: $10.14260 /$ jemds $/ 2017 / 805$ described here is exceptional, as it developed after surgical removal of the appendix for which an incidental carcinoid was found histologically involving the base.

\section{PATHOLOGICAL DISCUSSION}

After the first description of pneumatosis cystoides intestinalis in 1730 by Du Vernoy in autopsy specimens, these entities were named in 1825 by Mayer. Pneumatosis cystoides intestinalis diagnosis was first established by Hahn in 1899 and later its associated radiological findings were first described by Eaumann Schender in 1939.3,4 Pneumatosis cystoides intestinalis was previously reported as occurring most commonly in the small intestine; however, recent studies have shown that the colon is affected more frequently (46-62\%) versus the small intestine (15 - 26\%) respectively with only $7 \%$ of cases affecting both.5,6 Symptoms most commonly include abdominal pain, constipation and bloating as well as diarrhoea, mucous discharge and rectal bleeding. 7,8 Further, $\mathrm{Wu}$ et al found that extramural gas was most commonly localised to the submucosal layer (69.9\%) as opposed to the subserosal layer with $4 \%$ of cases involving gas in both the layers. ${ }^{3}$

Pneumatosis cystoides intestinalis could be primary in $15 \%$ of cases without obvious cause or secondary to other pathology in $85 \%$ of cases like mesenteric vascular disease, necrotising enterocolitis, inflammatory bowel disease and connective tissue disorder as scleroderma. Another cause is drug therapy with immunosuppressive and chemotherapeutic drugs. Also it can result as a complication of sigmoidoscopy, colonoscopy and post-surgical anastomosis. ${ }^{9}$ As is evident in the described case, where the development of pneumatosis cystoides intestinalis is thought to be secondary to appendicectomy.

Imaging studies which are useful in diagnosing pneumatosis cystoides intestinalis are plain abdominal $\mathrm{x}$ rays, opaque enema, computerised tomography, ultrasonography, MRI and colonoscopy. Among these abdominal x-rays is the most reliable examination. ${ }^{10}$ Though radiological examination detects most of these cases, pathological examination is a must in few cases, where endoscopy biopsy is warranted. Though pathological examination is a must, only few studies however have described the microscopic features. A larger study on microscopy will probably reveal features of prognostic importance. ${ }^{11}$ 


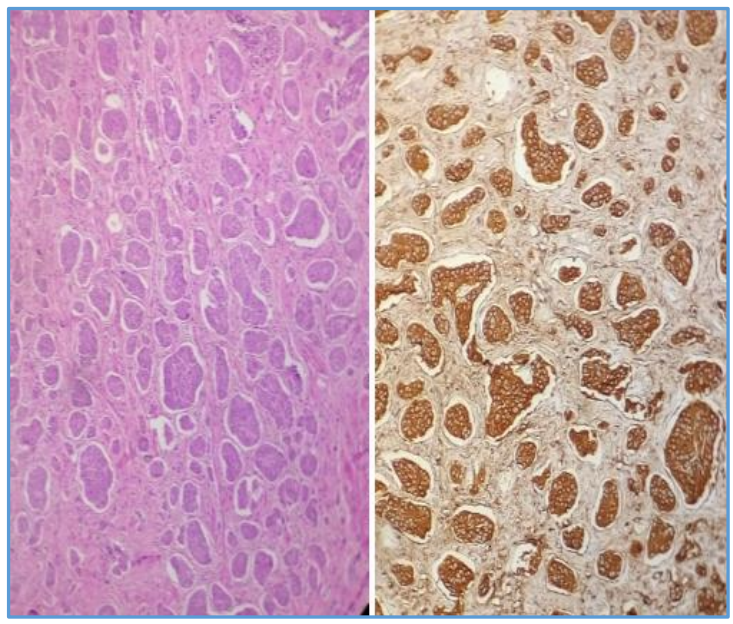

Figure 1. Low Power View of H and E Carcinoid Tumour with Chromogranin (IHC) Positive Stain

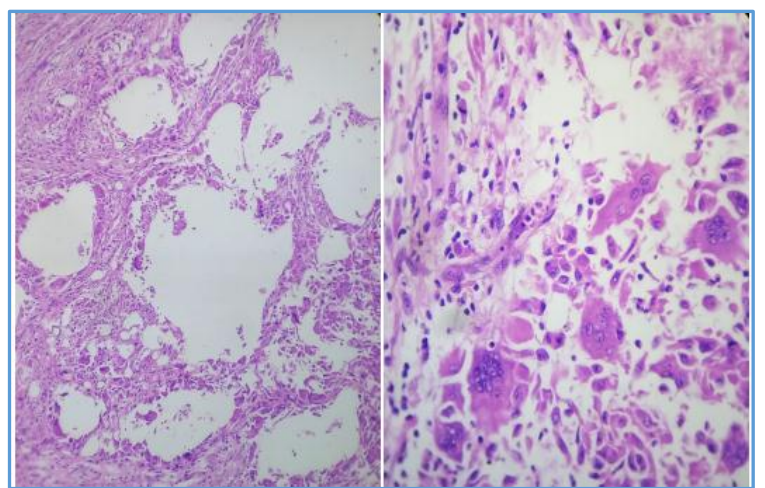

Figure 2. Low Power and High Power View of Cyst Spaces Lined by Multinucleated Giant Cells

\section{DISCUSSION OF MANAGEMENT}

Conservative approaches have been employed in patients with pneumatosis cystoides intestinalis, especially when asymptomatic and a benign underlying cause is known. Conservative methods include hyperbaric oxygen as routinely

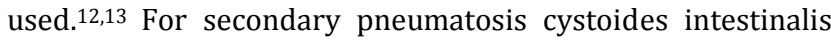
with or without complication, surgery is indicated.11 Diagnosing rare benign conditions can be difficult, especially where bowel cancer is part of the differential diagnosis. In such cases, a multidisciplinary approach is essential.

Balancing the risks and benefits of either committing to full oncological surgical resection or adopting, a more conservative approach needs to be fully balanced. In our case the potential risk of cancer involving the ileocaecal junction, especially with a previous history of low-grade neuroendocrine carcinoma of appendix was deemed too high to expect conservative management.

\section{FINAL DIAGNOSIS}

Pneumatosis Cystoides Intestinalis after Appendicectomy.

\section{Conclusion}

Our case demonstrates that pneumatosis cystoides intestinalis may often mimic sinister pathologies in terms of its presentation and clinical history. In our knowledge, this is the second reported case in literature of pneumatosis cystoides intestinalis associated with inflammatory changes following appendicectomy after the first published case report of Chris Vendryes et al. ${ }^{14}$ The incidental finding of carcinoid tumour in the appendix also makes this case interesting and necessitates the need for surgical intervention at this point.

\section{REFERENCES}

[1] Sakurai Y, Hikichi M, Isogaki J, et al. Pnematosis cystoides intestinalis associated with massive free air mimicking perforated diffuse peritonitis. World Journal of Gastroenterology 2008;14(43):6753-6.

[2] Rosai J. Rosai and Ackerman's surgical pathology. 9th edn. Missouri: Mosby 2005:797-8.

[3] Wu LL, Yang YS, Dou Y, et al. A systematic analysis of pneumatosis cystoides intestinalis. World Journal of Gastroenterology 2013;19(30):4973-8.

[4] Arikanoglu Z, Aygen E, Camci C, et al. Pneumatosis cystoides intestinalis: a single center experience. World Journal of Gastroenterology 2012;18(5):453-7.

[5] Horiuchi A, Akamatsu T, Mukawa K, et al. Case report: pneumatosis cystoides intestinalis associated with post - surgical bowel anastomosis: a report of three cases and review of the Japanese literature. Journal of Gastroenterology and Hepatology 1998;13(5):534-7.

[6] Morris MS, Gee AC, Cho SD, et al. Management and outcome of pneumatosis intestinalis. The American Journal of Surgery 2008;195(5):679-83.

[7] Heng Y, Schuffler MD, Haggitt RC, et al. Pneumatosis intestinalis: a review. The American Journal of Gastroenterolgy 1995;90(10):1747-58.

[8] Jamart J. Pneumatosis cystoides intestinalis. A statistical study of 919 cases. Acta Hepatogastroenterologica (Stuttg) 1979;26(5):41922.

[9] Saeed J. Pneumatosis cystoides intestinalis: a case report. Journal of Royal Medical Services 2011;18(4):55-7.

[10] Vaquerizo RPA, Martins CA, Garcia LMA, et al. Pneumatosis cystoides intestinalis. Revista Espanola De Enfermedades Digestivas 2006;98:959-61.

[11] Kumar SB, Padhy S, Poovizhi I, et al. An attempt to unravel features of pneumatosis cystoides intestinalis. Journal of Evolution of Medical and Dental Sciences 2014;3(13):3476-83.

[12] Mizoguchi F, Nanki T, Miyasaka N. Pneumatosis cystoides intestinalis following lupus enteritis and peritonitis. Internal Medicine 2008;47(13):1267-71.

[13] Tsujimoto T, Shioyama E, Moriya K, et al. Pneumatosis cystoides intestinalis following alpha-glucosidase inhibitor treatment: a case report and review of the literature. World Journal of Gastroenterology 2008;14(39):6087-92.

[14] Vendryes C, Hunter CJ, Harlan SR, et al. Pneumatosis intestinalis after laparoscopic appendectomy: case report and review of the literature. Journal of Pediatric Surgery 2011;46(11):e21-e4. 